\title{
Efficient construction of Streptococcus anginosus mutants in strains of clinical origin
}

\author{
Katarzyna Obszańska ${ }^{1} \cdot$ Izabella Kern-Zdanowicz ${ }^{1} \cdot$ Izabela Sitkiewicz $^{2}$ (D)
}

Received: 26 June 2018 /Revised: 28 August 2018 / Accepted: 13 September 2018 / Published online: 26 September 2018

(C) The Author(s) 2018

\begin{abstract}
Streptococcus anginosus group (SAG) is Gram-positive bacteria responsible for a number of purulent human infections such as brain and liver abscesses, which have been on the rise for last few decades. Although some virulence factors of SAG are described, they are mostly undefined and there are almost no methods for genetic manipulations of clinical SAG. Therefore, we presented various approaches to produce engineered strains of this poorly known group of streptococci. We developed a procedure of transformation characterized by transformation efficiency at the level of $10^{4}$ per $1 \mu \mathrm{g}$ DNA for certain strains. Moreover, mutagenesis for many SAG strain is possible based on the process of natural transformation. However, the usefulness of methods and their effectiveness are strain dependent.
\end{abstract}

Keywords Streptococcus anginosus $\cdot \mathrm{SAG} \cdot \mathrm{Natural}$ transformation $\cdot$ Electroporation

\section{Introduction}

Molecular experiments to study gene functions usually require tools for DNA and cell manipulation. Those tools include methods to introduce and stably maintain DNA in bacterial cells and methods to analyze the influence of artificial DNA constructs on the host. Microbiologists working with quite uniform on the molecular level laboratory organisms that share multiple traits, such as Escherichia coli K12 or Bacillus subtillis 168 derivatives, can utilize a wide spectrum of molecular methods appropriate for various studies. Techniques used for particular laboratory strain of $E$. coli will work with high probability with other laboratory strains of this species; however, clinical strains of E. coli can be difficult to handle. Those techniques have been used for many years and multiple alterations have been made to simplify and to adapt them to the particular models. Organisms less commonly used in research settings

Communicated by: Agnieszka Szalewska-Palasz

Izabela Sitkiewicz

i.sitkiewicz@nil.gov.pl

1 Department of Microbial Biochemistry, Institute of Biochemistry and Biophysics PAS, Warsaw, Poland

2 Department of Drug Biotechnology and Bioinformatics, National Medicines Institute, Chełmska 30/34, 00-725 Warsaw, Poland usually require special methods or treatments. Modified methods must be applied for common processes such as transformation or DNA isolation when additional steps like cell wall digestion with mutanolysin or lysostaphin must be applied. Modifications of methods for non-standard microorganisms, besides making them easier to use, lead to the development of specialized tools to study their biology. But unfortunately, many standard techniques are not available for non-laboratory species, or they are not optimized for use with clinical strains isolated from humans and animals. One of the microorganisms without well-defined conditions for genetic manipulation is streptococci that belong to anginosus group (SAG). SAG are oral bacteria, for years regarded as non-pathogenic viridans streptococci. However, in recent years, increased number of infections caused by these bacteria has been described (Obszanska et al. 2016; Sitkiewicz 2018).

Few different types of methods have been used to introduce foreign DNA into cells, such as use of natural competence (B. subtilis (Spizizen 1958)), chemical competence (E.coli (Mandel and Higa 1970)), transformation of protoplasts (B. subtilis (Chang and Cohen 1979)), or electrotransformation (Dower et al. 1988; Luchansky et al. 1988). These common methods used for transformation of laboratory strains might not be compatible with different species, but they could be a good basis for adaptation for other studied models. Many various factors could influence the results, especially in poorly characterized organisms. For non-characterized organisms, 
use of natural properties could be the best approach in genetic manipulation. One of the examples of such approach in molecular biology is the usage of natural transformation in Streptococcus pneumoniae, which was discovered and reported by Griffith (Griffith 1928) and later studied by Avery (Avery et al. 1944). The study of natural transformation in streptococci led to the discovery of the mechanism of this process mediated by a set of com genes encoding major elements required for competence state. Early reports divided Streptococcus genus into two classes "naturally competent" and "non-competent" according to their putative natural competence based on the PCR detection of the comCDE operon (Håvarstein et al. 1997). The first group included members of mitis/oralis and anginosus divisions, and the "non-competent" group includes the other, pyogenic, mutans, bovis, and salivarius.

In 1989, Jacob (Jacob et al. 1989) described factor which helped some of the non-spontaneously transformable streptococci strains to uptake foreign DNA. Nowadays, this factor is known as a pheromone, competence factor (CF), or competence stimulating peptide (CSP). Recently, Cook and Federle (2014) reviewed in details multiple pheromone sensing pathways and development of competence in multiple streptococcal and enterococcal species. Streptococcus anginosus group (SAG) and mitis streptococci utilize ComAB/ComCDE system, where processed ComC serves as pheromone peptide. ComC is a several amino acid long peptide and its sequence might differ in various strains, as it was shown elsewhere (Håvarstein et al. 1997). Besides, ComC is expressed as a pro-peptide and its signal sequence is removed during CSP secretion by ComAB, ABC transporter. The active form of the pheromone released to the environment interacts with membrane receptor ComD. As a consequence, ComD is autophosphorylated and transfers the phosphate signal to the response regulator ComE. Recognition of CSP by ComDE two-component system leads to induction of other competence genes, including $\operatorname{com} X . \operatorname{ComX}\left(\sigma^{\mathrm{X}}\right)$ is a streptococcal alternative sigma factor, in Streptococcus pyogenes assigned as SigX. ComX regulates expression of multiple genes required for DNA uptake and DNA integration into the host genome.

Bacteria susceptible to particular CSP could be nonsusceptible to others, so the system can be strain specific. It is the reason for noticeable variability in the transformation efficiency between strains of the same species. Analysis of com $C D E$ operon sequences from different strains and streptococcal species showed various variants of encoded CSP. However, over $50 \%$ identity of the whole operon between strains is crucial for cross-identification and efficient transformation. It is even more essential among SAG division than other streptococci. It is because of the mosaic structure of $\operatorname{com} C D E$ operon observed among SAG strains. Between regions of over $90 \%$ identity, there are blocks of hundreds base pair with 50 $60 \%$ identity. Moreover, these regions encompass both parts of the comC and part of comD (Håvarstein et al. 1997).
Recently, natural competence pathways are being described for streptococci that are unable to uptake DNA naturally from the environment. S. pyogenes, considered to be not naturally competent, encodes major proteins responsible for this process. Despite the fact that the activity of SigX was confirmed, the whole mechanism did not work properly. Uptake of DNA was blocked and unknown factors might influence on the process (MashburnWarren et al. 2012). Another study showed that for the full competence, $\sigma^{\mathrm{X}}$ is required together with ComW (Tovpeko and Morrison 2014). Although the role of ComW is still unclear, it is necessary for the stability of $\sigma^{\mathrm{X}}$ and deletion of the com $W$ gene decreases transformation efficiency (Luo et al. 2004). Another factor that influences $\sigma^{\mathrm{X}}$ is a $\operatorname{com} X$-inducing peptide (XIP). A precursor of XIP is encoded by coms, while the mature XIP is recognized by ComR and the complex of both proteins activates $\sigma^{\mathrm{X}}$ expression. The activity of ComR/ComS system is especially visible under specific growth conditions such as poor chemically defined media, or particular pH (Son et al. 2015).

Knowing about the possibility of natural SAG transformation, we attempted to develop an efficient method that allows not only for simple introducing of plasmid DNA but also for manipulation of the chromosomal gene content (gene disruption, gene substitution, gene deletion) in SAG of clinical origin.

We used recently sequenced Streptococcus anginosus 4194/05 and 980/01 strains isolated from human blood infections (sequences unpublished). These strains carry $\mathrm{F}$ Lancefield antigens and were sequenced in our laboratory. Genome analyses showed that both strains carry $\operatorname{com} A B$ operon encoding $\mathrm{ABC}$ transporter, com $C D E$ operon responsible for competence signaling mechanism, $\operatorname{com} X$ encoding competence sigma factor, and its regulator $\operatorname{com} W$. Although we found the major factors essential for the development of competence and there is some evidence of natural competence of oral streptococci including SAG (Shinozaki-Kuwahara et al. 2005; Petersen and Scheie 2010), we tested alternative techniques allowing to avoid caveats of natural transformation. The aim of transformation was the deletion of $\operatorname{cod} Y$ gene, encoding a global metabolic regulator and regulator of virulence in Gram-positive bacteria. It was chosen for test inactivation as it is present in virtually all SAG genomes we tested and was inactivated successfully in various streptococcal species without growth defects when grown in rich media (Malke et al. 2006; Lemos et al. 2008).

\section{Materials and methods}

\section{Strains}

Escherichia coli DH5 $\alpha$ was grown in liquid LB broth with aeration or on agar-solidified LB plates at $37{ }^{\circ} \mathrm{C}$. SAG strains used in these studies were described previously (Obszanska et al. 2016) and strain 4194/05_Camp was generated during 
this study. SAG strains were grown in BHI (Brain Heart Infusion, Oxoid) liquid medium, on BHI blood agar plates or Columbia plates with $5 \%$ sheep blood (Becton Dickinson) in the presence of $5 \% \mathrm{CO}_{2}$ at $37{ }^{\circ} \mathrm{C}$. Antibiotics were used at the various concentrations: erythromycin $5 \mu \mathrm{g} / \mathrm{ml}(\mathrm{SAG})$ and $50 \mu \mathrm{g} / \mathrm{ml}$ (E. coli), $25 \mu \mathrm{g} / \mathrm{ml}$ kanamycin (SAG), spectinomycin $120 \mu \mathrm{g} / \mathrm{ml}$ (E. coli and SAG), $10 \mu \mathrm{g} / \mathrm{ml}$ streptomycin (SAG), and tetracycline $10 \mu \mathrm{g} / \mathrm{ml}$ (E. coli). All SAG strains were stored in BHI with $15 \%$ glycerol at $-80^{\circ} \mathrm{C}$.

\section{DNA manipulations}

DNA isolation Chromosomal DNA or plasmid DNA was isolated from cells grown overnight using commercially available kits, Genomic Mini or Plasmid Mini (A\&A Biotechnology), respectively according to the manufacturer's protocol. Additionally, initial incubation of bacterial cells with lysozyme ( $0.2 \mathrm{mg} / \mathrm{ml}$, Sigma), mutanolysin ( $50 \mathrm{U} / \mathrm{ml}$, Sigma), and RNase $(0.1 \mathrm{mg} / \mathrm{ml}$, Sigma) was performed during isolation of DNA from SAG strains. Additional incubation with enzymes is routinely used during DNA isolation and is essential for removal of the cell wall of SAG cells.

\section{Plasmids and linear fragments of DNA used in transformation} pGKV2 $\left(\mathrm{Em}^{\mathrm{R}}\right.$ ) shuttle vector (van der Vossen et al. 1985) was used as the test plasmid for transformation efficiency. All plasmids used in this work are listed in Table 1.

The construction of plasmids used in the study for transformation is presented in Fig. 1. DNA fragments used for the construction were amplified using specific primers (Table 2). Reverse primer used to amplify upstream flank contained added overhang homologous to the start of an $s p c$ cassette. First, 781-bp fragment of the upstream flank of 4194/05 $\operatorname{cod} Y$ gene (left flank, L) and 1033-bp fragment containing spectinomycin resistance gene ( $s p c$ cassette) (Fig. 1) from plasmid pSL60 (Lukomski et al. 2000) were mixed 1:1 and used as a template in PCR reaction with primers LF and spcR. An amplified product that consisted of the left flank and $s p c$ cassette was cut with restriction enzymes, EcoRI and $K p n \mathrm{I}$, according to the manufacturer's protocol (Thermo), purified (A\&A Biotechnology), and cloned into EcoRI and KpnI digested vector pMT5 (Dmowski et al. 2018) to generate plasmid named pL. Next, the downstream flank of $\operatorname{cod} Y$ (right flank, R) was amplified with RF and RR primers. Forward primer (RF) contained an overhang homologous to the end of an $s p c$ cassette. The $939 \mathrm{bp}$ PCR product was then mixed 1:1 with the $s p c$ cassette and the mixture was used as a template for PCR amplification with primers space and RR. The amplified PCR product contained the $s p c$ resistance cassette with the downstream $\operatorname{cod} Y$ flank. Then the product was cut with KpnI, purified, and inserted into $\mathrm{pL}$ digested with $K p n I$. The orientation of the right flank was verified by PCR and sequencing. As a result, plasmid named pLR was obtained. pLR contained fragment of DNA consisted of the left flank, $s p c$ cassette, and the right flank (5'L-spc-R3' cassette). All primers used in this work are presented in Table 2.

To generate a linear fragment of DNA for transformation, the insert from pLR containing the 5' $\mathrm{L}-s p c-\mathrm{R} 3$ ' cassette was amplified with LF and RR primers. The linear PCR product was treated with $D p n$ I to eliminate residues of methylated vector or chromosomal DNA.

\section{Results and discussion}

A major goal of our study was to develop a protocol for efficient natural SAG transformation and utilize competence genes we found in clinical SAG genomes. However, for laboratory tests, we wanted to compare natural transformation efficiency with other methods of introducing DNA into SAG cells. In addition, development of efficient transformation scheme would be beneficial for not naturally competent clinical SAG strain. Electrotransformation was successfully adopted for many Gram-positive bacteria such as Lactococcus lactis (Holo and Nes 1989) and S. pyogenes (Sitkiewicz and Musser 2006); therefore, we started from standardization of electrotransformation protocol for SAG.

Electrotransformation To test if the DNA can be efficiently introduced to SAG cells by electrotransformation, we first prepared electrocompetent cells using modified protocols used for other streptococci (Holo and Nes 1989; Dunny et al. 1991; Smith et al. 1995; Sitkiewicz and Musser 2006). On the contrary to published methods, we used BHI rich medium for SAG cultivation with the addition of threonine and
Table 1 Plasmids used in this study

\begin{tabular}{|c|c|c|}
\hline Plasmid & Characteristic & Source \\
\hline pGKV2 & Shuttle vector, low copy number, ori $\mathrm{V}_{\mathrm{pwv} 01}, \mathrm{Em}^{\mathrm{R}}$ & (van der Vossen et al. 1985) \\
\hline pMT5 & $\begin{array}{l}\text { pUC18 with bla replaced by the tet gene from } \\
\text { pACYC184; oriV } \mathrm{pMB}_{\mathrm{pMB}}, \mathrm{Tc}^{\mathrm{R}}\end{array}$ & (Dmowski M et al. 2018) \\
\hline $\mathrm{pL}$ & EcoRI-L:spc ${ }_{-K p n I}$ cloned into pMT5 & This work \\
\hline pLR & 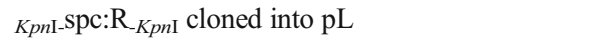 & This work \\
\hline pSL60 & Source od spectinomycin resistance gene & (Lukomski et al. 2000) \\
\hline
\end{tabular}



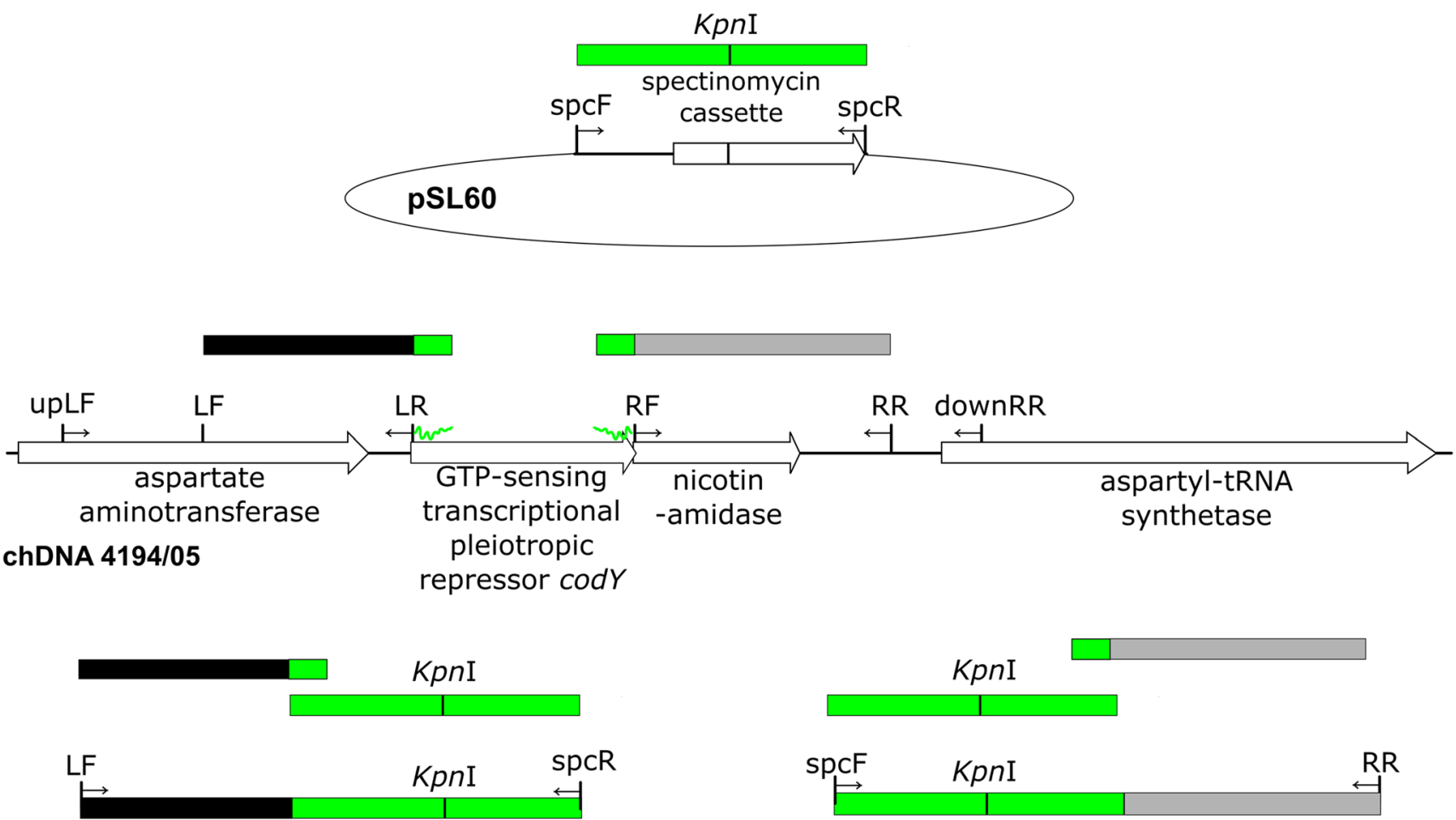

PCR product

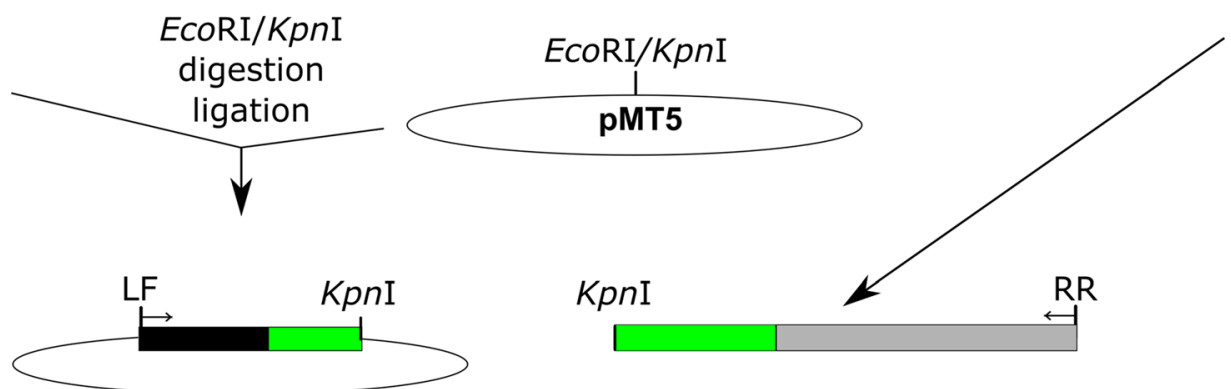

$\mathrm{pL}$

KpnI

digestion
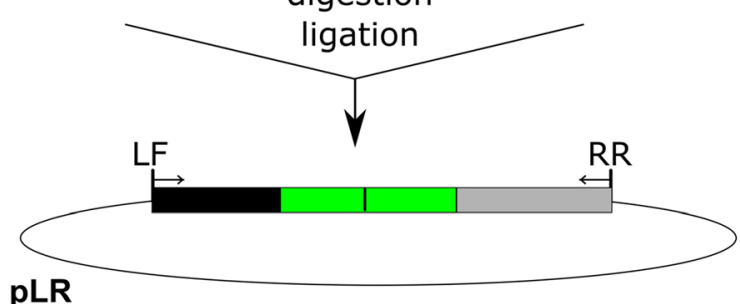

Fig. 1 Construction of the hybrid fragment containing upstream and downstream flanks of $\operatorname{cod} \mathrm{Y}$ gene with spectinomycin resistance cassette (green) used for SAG test transformations and gene inactivation. DNA fragments used for the construction were amplified using specific primers. Reverse primer used to amplify upstream flank contained added overhang homologous to the start of an $s p c$ cassette. A fragment of the upstream flank of 4194/05 codY gene (left flank, L) and fragment containing spectinomycin resistance gene ( $s p c$ cassette) from plasmid pSL60 were mixed 1:1 and used as a template in PCR reaction. An amplified product that consisted of the left flank and $s p c$ cassette was cut with restriction enzymes, EcoRI and $K p n I$, and cloned to generate plasmid

named pL. Next, the downstream flank of $\operatorname{cod} Y$ (right flank, R) was amplified with RF and RR primers. Forward primer (RF) contained an overhang homologous to the end of an $s p c$ cassette. The PCR product was then mixed 1:1 with the $s p c$ cassette and the mixture was used as a template for PCR amplification. The amplified PCR product contained the $s p c$ resistance cassette with the downstream $\operatorname{cod} Y$ flank. Then the product was cut with $K p n I$, purified, and inserted into $\mathrm{pL}$ digested with $K p n I$. The orientation of the right flank was verified by PCR and sequencing. As a result, plasmid named pLR was obtained. pLR contained fragment of DNA consisted of the left flank, $s p c$ cassette, and the right flank (5'L-spc-R3' cassette) 
Table 2 Primers used in this study

\begin{tabular}{ll}
\hline Primer & Sequence $5^{\prime} \rightarrow 3^{\prime}$ \\
\hline LF & ATAGAATTCTGATGGACGGTGAGAAA \\
& CATACGGCTATCG \\
LR & GTTATAGTTATTATAACATGTATTCCCG \\
& GGCATAATTACCTCGCATATAATC \\
& TTATTGATTATATC \\
spcF & CCCGGGAATACATGTTATAATAACTAT \\
& AACTAAT \\
spcR & CCCGGGTTATAATTTTTTTAATCTGTTA \\
& TTT \\
RF & TTAAATAACAGATTAAAAAAATTATAA \\
& CCCGGGTGATGACAAAAGCATTGA \\
RR & TTTCGATTG \\
upLF & CTTTACTACGTAAATCTATGACCATAG \\
downRR & CTCTAAAC \\
comDE_F & AGCGCCAGATGAGGTGATTCATGAC \\
comDE_R & TGAAGCAGTCCTTCTCGGTCTCGTAG \\
\hline
\end{tabular}

glycine. Simultaneous medium supplementation by threonine and glycine was intended to influence on cell wall synthesis. The initial test medium consisted of BHI with $0.5 \mathrm{M}$ sucrose, $40 \mathrm{mM}$ DL-threonine, and 0.1 M glycine. Bacteria were grown without aeration until the culture reached $\mathrm{OD}_{600}$ ca. 0.3 , indicating the early exponential phase of growth. The culture was chilled on the ice for $30 \mathrm{~min}$ and cells were collected by centrifugation at $4{ }^{\circ} \mathrm{C}$. The supernatant was removed, the bacterial pellet was washed twice using cold $0.5 \mathrm{M}$ sucrose, and finally, bacteria were re-suspended in $0.5 \mathrm{M}$ sucrose with $15 \%$ glycerol. The bacterial suspension was divided into single-use portions and frozen at $-80{ }^{\circ} \mathrm{C}$ or used directly for electrotransformation. Freshly prepared or thawed on the ice $50 \mu \mathrm{l}$ portions of competent cells were added to cold electroporation $0.1 \mathrm{~cm}$ cuvettes. Then ca. 200 ng of control plasmid pGKV2 was added to the cuvette. Bacteria with DNA were incubated on the ice for $30 \mathrm{~min}$. Next, cuvette was inserted into a sample chamber in Gene Pulser Bio-Rad system and electric pulse was applied with the capacitance of $25 \mu \mathrm{F}$, the voltage of $2.5 \mathrm{kV}$, and resistance of $200 \Omega$. Warm medium with sucrose (without antibiotics) was added to bacteria immediately after the pulse. Bacteria were incubated for about $3 \mathrm{~h}$ and then plated onto the selective medium with erythromycin. Transformation efficiency was in the range of $10^{2}$ per $1 \mu \mathrm{g}$ plasmid DNA.

Despite the fact that the cells prepared using this method exhibited low competence, the bacterial culture grew poorly in the test medium. Therefore, we analyzed which of the medium components is crucial for growth and transformation efficiency. We checked several variants of the media: supplemented or not with glycine, with different concentration of sucrose, and with the presence of L-, D-, or DL-isomers of threonine and incubation in presence of an increased concentration of $\mathrm{CO}_{2}$ during growth in the supplemented medium.

Interestingly, we observed that growth of test 4194/05 strain in the supplemented medium was reduced by at least $50 \%$ compared to growth in medium without any additional substance. Elimination of glycine from the medium supplemented by sucrose and threonine significantly improved 4194/05 strain growth rate. However, no transformants were observed on selective medium after multiple independent attempts of electrotransformation of competent cells prepared without glycine and using control plasmid pGKV2. Therefore, the addition of glycine seems to be crucial for preparation of SAG electrocompetent cells. Moreover, we noticed that elimination of sucrose with the simultaneous presence of threonine and glycine positively influenced on the growth of 4194/05 strain. Cells cultivated in such composed medium gave on average of 24 transformants $/ \mu \mathrm{g}$ of plasmid DNA. Then, we tested medium supplemented by a lower concentration of sucrose $(0.25 \mathrm{M}$, $40 \mathrm{mM}$ DL-threonine, $0.1 \mathrm{M}$ glycine) since sucrose could protect cells with defective cell wall caused by treating by glycine and threonine. In result, we observed transformation efficiency in the range of $10^{4}$ per $1 \mu \mathrm{g}$ plasmid DNA. Next, we tested the influence of threonine isoform on the transformation efficiency. D-threonine supplementation seemed to worsen transformation level. Addition of DL- or L-threonine to the medium resulted in the same transformation efficiency, ca. $2 \times 10^{4}$ transformants/ $\mu \mathrm{g}$ of plasmid DNA. We also tested an influence of the electric pulse parameters on the transformation efficiency. Higher resistance used during the electroporation decreased slightly the average transformation efficiency: $200 \Omega, 2.3 \times 10^{3} ; 400 \Omega$, $1.5 \times 10^{3}$; and $600 \Omega, 5 \times 10^{2}$ transformants $/ \mu$ g plasmid DNA. Incubation in presence of $5 \% \mathrm{CO}_{2}$ was crucial for the growth of 4194/05 strain in restricted conditions caused by sucrose, glycine, and threonine. In conclusion, the highest transformation efficiency obtained for 4194/05 strain was therefore around $10^{4}$ transformants per $1 \mu \mathrm{g}$ of pGKV2 plasmid DNA. Summary of transformation efficiencies obtained for 4194/05 are presented in Tables 3 and 4.

Using electrocompetent 4194/05 cells, we were unable to obtain transformants/integrants after attempts to introduce linear DNA 5'L-spc-R3'. It suggested degradation of a linear DNA, a defect in recombination process, or too low efficiency to obtain a mutant with a linear fragment integrated via double crossing-over into the chromosome.

To check if the recombination system of 4194/05 strain works properly, we used pLR plasmid (with 5'L-spc-R3' cassette), which is unable to replicate in Gram-positive bacteria. Recombination machinery of 4194/05 strain after the uptake of pLR should force into integration the plasmid into the chromosome, most probably via Campbell recombination. As a result of the first transformation trial using previously prepared electrocompetent cells, characterized by plasmid transformation 
Table 3 Electrotransformation efficiency of 4194/05 strain using control plasmid pGKV2 [per 1- $\mu$ g DNA]. We used various batches of electrocompetent cells. Testing medium composition

Transformation efficiency per $1 \mu \mathrm{g}$ of plasmid DNA. Pulse condition $-2.5 \mathrm{kV}, 25 \mu \mathrm{F}, 200 \Omega$

\begin{tabular}{|c|c|c|c|c|}
\hline $0,5 \mathrm{M}$ succrose & $0,5 \mathrm{M}$ succrose & $0,25 \mathrm{M}$ succrose & $0,25 \mathrm{M}$ succrose & --- \\
\hline 40mM L-Thr & 40mM L-Thr & 40mM L-Thr & 40mM DL-Thr & 40mM DL-Thr \\
\hline --- & $0,1 \mathrm{M}$ glycine & $0,1 \mathrm{M}$ glycine & $0,1 \mathrm{M}$ glycine & $0,1 \mathrm{M}$ glycine \\
\hline 0 & $1.2 \times 10^{2}$ & $8.4 \times 10^{3}$ & $1.2 \times 10^{4}$ & $2.3 \times 10^{1}$ \\
\hline 0 & $9.8 \times 10^{2}$ & $1.2 \times 10^{4}$ & $2.2 \times 10^{4}$ & $1.8 \times 10^{1}$ \\
\hline 0 & $6.6 \times 10^{2}$ & $7.9 \times 10^{3}$ & $1.2 \times 10^{4}$ & $3.3 \times 10^{1}$ \\
\hline 0 & $2.0 \times 10^{1}$ & $1.1 \times 10^{4}$ & $1.6 \times 10^{3}$ & $4.0 \times 10^{1}$ \\
\hline & & $1.7 \times 10^{4}$ & $9.3 \times 10^{3}$ & \\
\hline
\end{tabular}

efficiency in the range $10^{4}$, several transformants grew on selective medium with spectinomycin. The downstream analysis showed that the whole vector was incorporated into the chromosome of 4194/05 strain, resulting 4194/05 Camp. Integration of pLR into the chromosome was verified by PCR using specific primers (upLF and downRR). This result indicated that 4194/05 strain is able to integrate foreign DNA into the chromosome. The most probable explanation of inability to uncover colonies on selective plates after transformation with linear DNA is the low-efficiency transformation of 4194/05 compared with the frequency of double crossing-over. It seems that double recombination in the genetic background of 4194/ 05 strain occurs less frequently than the frequency of plasmid introduction into 4194/05 competent cells.

We analyzed the ability of another SAG strain to efficient transformation by media modification. We verified the besttested conditions for electroporation procedure in case of another SAG strain, 980/01. Briefly, the strain was cultured in BHI with the presence of $40 \mathrm{mM}$ DL-threonine, $0.1 \mathrm{M}$ glycine, and $0.25 \mathrm{M}$ sucrose, washed by $0.5 \mathrm{M}$ sucrose, and treated by electric pulse $(25 \mu \mathrm{F}, 2.5 \mathrm{kV}, 200 \Omega, 0.1 \mathrm{~cm}$ cuvettes). Using control plasmid pGKV2, the average electroporation efficiency was $9 \times 10^{3} / \mu \mathrm{g}$ DNA. The reveled efficiency of 980/01 strain was slightly lower than the efficiency of 4194/ 05 strain $\left(2 \times 10^{4} / \mu \mathrm{g}\right.$ plasmid DNA). This result showed also that using tested protocol competent, SAG cells were obtained

Table 4 Electrotransformation efficiency of 4194/05 strain using control plasmid pGKV2 [per 1- $\mu \mathrm{g}$ DNA]. We used various batches of electrocompetent cells. Testing pulse condition

\begin{tabular}{|c|c|c|}
\hline \multicolumn{3}{|c|}{$\begin{array}{l}\text { Transformation efficiency per } 1 \mu \mathrm{g} \text { of } \\
\text { plasmid DNA. Medium } 0.25 \mathrm{M} \text { sucrose, } \\
40 \mathrm{mM} \text { DL-Thr, } 0.1 \mathrm{M} \text { glycine. Pulse } \\
2.5 \mathrm{kV}, 25 \mu \mathrm{F}\end{array}$} \\
\hline $200 \Omega$ & $400 \Omega$ & $600 \Omega$ \\
\hline $4.4 \times 10^{2}$ & $9.2 \times 10^{2}$ & $8.0 \times 10^{2}$ \\
\hline $7.8 \times 10^{2}$ & $7.0 \times 10^{2}$ & $5.2 \times 10^{2}$ \\
\hline $1.6 \times 10^{3}$ & $1.6 \times 10^{3}$ & $4.4 \times 10^{2}$ \\
\hline $6.5 \times 10^{3}$ & $2.8 \times 10^{3}$ & $4.0 \times 10^{2}$ \\
\hline $1.7 \times 10^{3}$ & $1.3 \times 10^{4}$ & \\
\hline
\end{tabular}

with the similar effectiveness. Although the transformation ability of both strains was comparable, we additionally examined if 980/01 strain could be electrotransformed with linear DNA. The electroporation procedure was repeated using the 5'L-spc-R3' cassette amplified on the pLR plasmid template. Transformants were selected on medium with spectinomycin. After incubation, about 100 spectinomycin resistant colonies grew onto selective medium. Further analysis, using primer pairs upLF and spcR, or spcF and downRR, for $s p c$ cassette and for flanks of deleted $c o d Y$ gene, verified replacement of the $\operatorname{cod} Y$ gene by spectinomycin resistance cassette in $980 / 01$ strain in ca. $50 \%$ of transformants.

Interestingly, spectinomycin resistant colonies grew on the medium with spectinomycin concentration $2 \times$ MIC (minimal inhibitory concentration) for the tested strains without introduced $s p c$ cassette. Spectinomycin resistance is based on blocking of protein translation and the antibiotic interacts with a small subunit of the bacterial ribosome. Presence of spontaneous spectinomycin resistance might be explained by a simple mutation of the gene encoding a ribosomal protein which interacts with the antibiotic. On the other hand, SAG may encode an unknown enzyme which modifies the antibiotic or may encode not-specific efflux pump, which provides antibiotic molecules transport out of the cell.

Transformation of protoplast Since transformation efficiency of 4194/05 electrocompetent cells was low, we decided to test alternative approach of protoplast transformation. Thus, an overnight culture of 4194/05 strain in BHI was collected by centrifugation (10 min, $3000 \mathrm{rcf}$, at room temperature). Then, bacteria were re-suspend in $5 \mathrm{ml}$ of protoplastization buffer (BHI supplemented with SMM buffer (0.5 M sucrose, $0.02 \mathrm{M}$ maleate, 0.02 $\left.\mathrm{MgCl}_{2}\right)$ ) (Woskow and Kondo 1987) or saline solution. Sample from saline solution was diluted and plated onto BHI medium to count bacteria. Cells in protoplastization buffer were incubated with gentle shaking at $37^{\circ} \mathrm{C}$. Additionally, cells were treated by enzymes removing cell wall, lysozyme (10 $\mathrm{mg} / \mathrm{ml}$, Sigma), and mutanolysin ( $25 \mathrm{U} / \mathrm{ml}$, Sigma). To prevent protoplasts from the rupture after cell wall digestion, they were stored into isotonic 
solution, such as BHI medium supplemented with $0.5 \mathrm{M}$ sucrose, $0.02 \mathrm{M}$ maleate, and $0.02 \mathrm{M} \mathrm{Mg}^{2+}$ ions.

Initially, we examined if protoplasts were generated in tested conditions and if they could regenerate after plating onto the solid medium. Bacteria re-suspended in protoplastization buffer were incubated at $37{ }^{\circ} \mathrm{C}$ with gentle mixing. After $30 \mathrm{~min}, 2$ or $4 \mathrm{~h}$ of incubation samples were collected. Each sample was diluted from $10^{-5}$ to $10^{-10}$ in $\mathrm{H}_{2} \mathrm{O}$ and BHI supplemented by SMM. Then, dilutions were plated onto two variants of medium BHI (standard broth) or BHI with $0.5 \mathrm{M}$ sucrose (regeneration broth). A number of bacteria diluted in BHI supplemented by SMM and grown onto BHI with sucrose indicated the number of all bacteria. A number of bacteria diluted in $\mathrm{H}_{2} \mathrm{O}$ and grown onto $\mathrm{BHI}$ indicated the number of bacteria that were not in protoplast stage. Protoplastization of the cells was verified by microscope observation.

Three independent trials were performed. On average, after $30 \mathrm{~min}$, cell wall digestion of $4194 / 05$ strain ca. $67 \%\left(15 \times 10^{13}\right.$ vs $5 \times 10^{13}$ ) of cells were cell wall free (cfu on regeneration broth vs cfu on standard broth). Two hours of incubation gave around $99.6 \%$ cell wall free cells $\left(15 \times 10^{12}\right.$ vs $\left.6 \times 10^{10}\right)$. A similar result, of $99.9 \%$ of cell wall free cells, was obtained after $4 \mathrm{~h}$ of incubation. However, the number of all cells dramatically decreased $\left(6 \times 10^{10}\right.$ vs $\left.2 \times 10^{7}\right)$ after 4 -h incubation in protoplastization buffer. Therefore, in further tests of protocol development, the incubation was carried out for $2 \mathrm{~h}$. For electroporation, after 2-h incubation, protoplasts were washed in $0.5 \mathrm{M}$ sodium succinate and centrifuged for $10 \mathrm{~min}$ at 3000 rcf and re-suspended in sodium succinate. Then protoplasts were transferred to cold $0.2-\mathrm{cm}$ gap cuvette. Approximately $1 \mu \mathrm{g}$ of control plasmid pGKV2 or chromosomal DNA of 4194/05_Camp strain (with marker $s p c$ cassette) was added. After $30 \mathrm{~min}$ on ice, electroporation was performed. Initial parameters were capacitance of $25 \mu \mathrm{F}$, the resistance of $400 \Omega$, and voltage of $0.5 \mathrm{kV}$. Subsequent attempts tested voltage of $0.2,1$, and $2 \mathrm{kV}$ and resistance of 200 and $600 \Omega$. BHI medium supplemented by SMM was added to bacteria immediately after the electric pulse. Bacteria were incubated for $6 \mathrm{~h}$ in growth medium supplemented by $0.25 \mathrm{M}$ sucrose to allow cell wall regeneration. Then, they were plated onto selective medium.

We did not observe regeneration after the shock. After ten trials with different electric conditions, the number of cfu grown onto regeneration broth was comparable to the number of cfu onto standard broth (on average $4.6 \times 10^{7}$ vs $6.6 \times 10^{7}$ ). Although the low strength of electric pulse was used, it could damage protoplasts. Whereas, colonies grown onto broth originated from the part of not-digested cells. The second reason might be that the regeneration broth was good enough for regeneration protoplasts after cell wall digestion but not for recovering them after an electric shock.

In conclusion, we were unable to setup electrotransformation parameters that allowed 4194/05 strain to survive the electric pulse. Protoplasts not subjected to the electric pulse were able to regenerate and form colonies, but cells after electric pulse were not. We think that SAG cells require very gentle parameters of the electric pulse to be able to regenerate afterward. In our hands, the protoplast electrotransformation does not work as a way to introduce DNA into SAG cells.

Natural transformation Rather unsuccessful attempts with efficient electrotransformation of SAG cells or protoplasts led us to tests of the efficiency of natural transformation. Replacement of the target gene by resistance marker by the double recombination was observed in other SAG strains (Bauer et al. 2018), as a result of the natural transformation. Putative natural competent SAG strains could be selected based on the detection of com operons in their genomes. Analysis of 4194/05 genome revealed the presence of $\operatorname{com} A B$ and $\operatorname{com} C D E$ operons. Therefore, putative natural CSP (product of comC gene) should be present in the 4194/ 05 culture medium. An appropriate amount of CSP in culture medium should induce competent state based on quorum sensing principles. So, the addition of overnight culture medium to fresh bacterial culture might increase the concentration of CSP. We attempted to induce natural competence of 4194/ 05 strain without and with using the post-culture medium. The post-culture medium was sterilized neither through autoclaving nor through filtration as temperature could inactivate the peptide, and membrane could bind the peptide. Briefly, an overnight culture of 4194/05 strain was diluted 1:10 in fresh BHI and incubated for $70 \mathrm{~min}$ at $37^{\circ} \mathrm{C}$. Then, chromosomal DNA of 4194/05_Camp (200-400 ng/ml), either with or without a post-culture medium (1:10), was added. After 3-h incubation, bacteria were plated onto the selective medium with spectinomycin. We did not observe any recombinants of 4194/ 05 strain after three independent trials of bacteria incubation with DNA, neither with nor without the addition of postculture medium.

Next attempt of enforcing competence state of 4194/05 strain was based on recent reports. As it was observed, the sub-lethal concentration of antibiotics activates stress response and expression of genes located near the oriC including competence genes (Prudhomme et al. 2006; Slager et al. 2014). For competence stimulation of $4194 / 05$ strain, we used $25 \mu \mathrm{g} / \mathrm{ml}$ kanamycin and $10 \mu \mathrm{g} / \mathrm{ml}$ streptomycin. Like previously, diluted bacteria culture was incubated $70 \mathrm{~min}$, then chromosomal DNA of 4194/05_Camp and antibiotics were added and further incubation was carried out. After $3 \mathrm{~h}$ bacteria were plated onto selective broth. Medium supplementation by a sub-lethal concentration of antibiotics was not successful as well, no recombinants of 4194/05 strain grew onto selective broth. This failure could be explained by that the concentration of antibiotics did not provide proper stress condition and DNA uptake system was not induced.

In the last approach towards induction of 4194/05 strain competence, we used artificial CSP. Peptide sequence 
Table 5 Strains tested for the transformation ability using pheromone peptide. "-" denotes lack of colonies after incubation with DNa or DNA and CPS; “+” the transformation denotes positive result of

\begin{tabular}{lll}
\hline Strain & DNA + CSP & DNA only \\
\hline $2111 / 07$ & - & - \\
$2088 / 07$ & + & - \\
$980 / 01$ & + & - \\
$3577 / 10$ & - & - \\
$647 / 10$ & - & - \\
$4020 / 05$ & + & + \\
$2160 / 05$ & + & - \\
$4194 / 05$ & - & - \\
$4093 / 08$ & - & - \\
$2662 / 08$ & - & - \\
$3865 / 07$ & - & - \\
$2721 / 07$ & + & + \\
$2189 / 01$ & - & - \\
$3859 / 13$ & - & - \\
$178 / 09$ & + & + \\
$1365 / 09$ & + & + \\
$5604 / 13$ & - & - \\
$5652 / 09$ & - & - \\
\hline & & \\
\hline
\end{tabular}

DSRIRMGFDFSKLFGK (Lipopharm) was based on genomic sequence of 4194/05 strain and matched the sequence used and published by Håvarstein (Håvarstein et al. 1997). Firstly, refreshed overnight culture (1:10) was incubated for $2 \mathrm{~h}$ at $37^{\circ} \mathrm{C}$. Next natural competence was induced by addition, to the bacterial culture, CSP at the concentration $5 \mathrm{ng} / \mathrm{ml}$, $50 \mathrm{ng} / \mathrm{ml}$ or $0.5 \mu \mathrm{g} / \mathrm{ml}$ together either with chromosomal DNA of 4194/05_Camp (ca. $3 \mu \mathrm{g} / \mathrm{ml}$ ) or with the linear PCR product of 5'L-spc-R3' cassette (200-400 ng/ml). Then, bacteria were incubated for $3 \mathrm{~h}$ at $37{ }^{\circ} \mathrm{C}$ and plated onto selective medium. No positive results were obtained from two independent transformation tests. We hypothesized that either competence system of this particular strain did not work properly or synthetic peptide was inactive.

To check if the synthetic CSP was functional, we tested its activity on 17 other SAG strains from our collection (Obszanska et al. 2016). Two-hour cultures were divided into three separate samples. Each was supplemented by (i) CSP and chromosomal DNA of 4194/05_Camp, (ii) only chromosomal DNA, or (iii) only CSP. The final concentration of CSP was $100 \mathrm{ng} / \mathrm{ml}$ and chromosomal DNA ca. $3 \mu \mathrm{g} / \mathrm{ml}$. After 3-h incubation, samples were plated onto selective medium. In the first variant (CSP and DNA), we obtained recombinants in case of seven strains $(980 / 01,2160 / 05,4020 / 05,2088 / 07$, $2721 / 07,178 / 09,1365 / 09)$. We checked and verified the presence of $c o m D E$ genes in genomes of these seven strains using specific primers. Since the unpublished genomic sequences of few of those strains were available for our laboratory $(980 / 01$, 4020/05, 2088/07, 178/09, 1365/09), we could verify also a sequence of $\operatorname{com} C$ present in particular strains. The identical sequence to synthetic CSP was observed in genomes of 980/ 01, 4020/05, 178/09, and 1365/09 strains. Interestingly, none known homolog of $\operatorname{com} C$ was detected in the genome sequence of 2088/07 strain. Transformation efficiency for strains was in the range of 1 recombinant to 100 recombinants per $1 \mu \mathrm{g}$ of chromosomal DNA. Four (4020/05, 2721/07, 178/ $09,1365 / 09)$ of seven strains that gave positive results in the first variant of the experiment yielded also colonies after incubation with DNA alone, without the addition of synthetic CPS (Table 5). However, the number of spectinomycin colonies was at least twofold lower than in the first variant with synthetic CSP. These results indicated that the transformation efficiency using synthetic CSP is strain dependent. We verified the presence of spectinomycin resistance cassette in PCR using specific primers and chromosomal DNA of recombinants as templates. In addition to the transformation using chromosomal DNA, we tested transformation and integration of the linear PCR product. We decided to use strains that were shown to be the most efficient in tests with chromosomal DNA (4020/05 and 1365/09). The workflow for the transformation with linear 5'L-spc-R3' cassette (200$400 \mathrm{ng} / \mathrm{ml}$ ) was the same as in transformation with chromosomal DNA. As a result of experiment, three spectinomycin, resistant colonies of 4020/05 strain, and two of 1365/09 strain were obtained The presence of $s p c$ cassette after transformation was verified by PCR.

\section{Summary}

We presented three different approaches for genetic engineering of SAG strains. Two tested strains yielded comparable transformation efficiency; the protoplast transformation was unsuccessful, as we were unable to regenerate protoplasts. The most promising results were obtained for natural transformation with CPS, where we were able to introduce foreign DNA to 7 of 17 tested strains. Our results showed large differences in behavior of clinical SAG strains. Described methods of genetic manipulation were not always appropriate for all strains and without detailed genomic analysis, we could only speculate what are the reasons. The differences in strain behavior may be caused by the differences in their genomic sequence and unknown regulators could play a significant role in some SAG.

Authors' contribution $\mathrm{KO}$ designed the study, performed the experiments, analyzed the data, and wrote the manuscript; IKZ analyzed the data and wrote the manuscript; and IS designed the study, analyzed the data, and wrote the manuscript.

Funding The study was funded by grants N N401 535940 form the National Science Center to IS and 2012/07/N/NZ2/00113 to KO. 


\section{Compliance with ethical standards}

Conflict of interest The authors declare that they have no conflict of interest.

Open Access This article is distributed under the terms of the Creative Commons Attribution 4.0 International License (http:// creativecommons.org/licenses/by/4.0/), which permits unrestricted use, distribution, and reproduction in any medium, provided you give appropriate credit to the original author(s) and the source, provide a link to the Creative Commons license, and indicate if changes were made.

\section{References}

Avery OT, Macleod CM, McCarty M (1944) Studies on the chemical nature of the substance inducing transformation of pneumococcal types: induction of transformation by a desoxyribonucleic acid fraction isolated from pneumococcus type III. J Exp Med 79:137-158

Bauer R, Mauerer S, Grempels A, Spellerberg B (2018) The competence system of Streptococcus anginosus and its use for genetic engineering. Mol Oral Microbiol 33:194-202

Chang S, Cohen SN (1979) High frequency transformation of Bacillus subtilis protoplasts by plasmid DNA. MGG Mol Gen Genet 168: $111-115$

Cook LC, Federle MJ (2014) Peptide pheromone signaling in Streptococcus and Enterococcus. FEMS Microbiol Rev 38:473-492

Dmowski M, Gołębiewski M, Kern-Zdanowicz I (2018) Characteristics of the conjugative transfer system of the IncM plasmid pCTX-M3 and identification of its putative regulators. J Bacteriol e00234-18. https://doi.org/10.1128/JB.00234-18

Dower WJ, Miller JF, Ragsdale CW (1988) High efficiency transformation of E. coli by high voltage electroporation. Nucleic Acids Res 16:6127-6145

Dunny GM, Lee LN, LeBlanc DJ (1991) Improved electroporation and cloning vector system for gram-positive bacteria. Appl Environ Microbiol 57:1194-1201

Griffith F (1928) The significance of pneumococcal types. J Hyg (Lond) 27:113-159

Håvarstein LS, Hakenbeck R, Gaustad P (1997) Natural competence in the genus Streptococcus: evidence that streptococci can change pherotype by interspecies recombinational exchanges. J Bacteriol 179:6589-6594

Holo H, Nes IF (1989) High-frequency transformation, by electroporation, of Lactococcus lactis subsp. cremoris grown with glycine in osmotically stabilized media. Appl Environ Microbiol 55:31193123

Jacob AE, Horton WA, Drucker DB (1989) Genetic transformation in some cariogenic Streptococcus milleri. Microbios 60:167-175

Lemos JA, Nascimento MM, Lin VK, Abranches J, Burne RA (2008) Global regulation by (p)ppGpp and CodY in Streptococcus mutans. J Bacteriol 190:5291-5299

Luchansky JB, Muriana PM, Klaenhammer TR (1988) Application of electroporation for transfer of plasmid DNA to Lactobacillus, Lactococcus, Leuconostoc, Listeria, Pediococcus, Bacillus, Staphylococcus, Enterococcus and Propionibacterium. Mol Microbiol 2:637-646
Lukomski S, Hoe NP, Abdi I, Rurangirwa J, Kordari P, Liu M et al (2000) Nonpolar inactivation of the hypervariable streptococcal inhibitor of complement gene (sic) in serotype M1 Streptococcus pyogenes significantly decreases mouse mucosal colonization. Infect Immun 68: $535-542$

Luo P, Li H, Morrison DA (2004) Identification of ComW as a new component in the regulation of genetic transformation in Streptococcus pneumoniae. Mol Microbiol 54:172-183

Malke H, Steiner K, McShan WM, Ferretti JJ (2006) Linking the nutritional status of Streptococcus pyogenes to alteration of transcriptional gene expression: the action of CodY and RelA. Int J Med Microbiol 296:259-275

Mandel M, Higa A (1970) Calcium-dependent bacteriophage DNA infection. J Mol Biol 53:159-162

Mashburn-Warren L, Morrison D a, Federle MJ (2012) The cryptic competence pathway in Streptococcus pyogenes is controlled by a peptide pheromone. J Bacteriol 194:4589-4600

Obszanska K, Kern-Zdanowicz I, Kozinska A, Machura K, Stefaniuk E, Sitkiewicz I (2016) Streptococcus anginosus (milleri) group strains isolated in Poland (1996-2012) and their antibiotic resistance patterns. Polish J Microbiol 65:33-41

Petersen FC, Scheie AA (2010) Natural transformation of oral streptococci. Methods Mol Biol 666:167-180

Prudhomme M, Attaiech L, Sanchez G, Martin B, Claverys J-P (2006) Antibiotic stress induces genetic transformability in the human pathogen Streptococcus pneumoniae. Science 313:89-92

Shinozaki-Kuwahara N, Shiroza T, Hayakawa M, Abiko Y, Fukushima K (2005) Expression of the gtfI gene from Streptococcus sobrinus in Streptococcus anginosus using integration-mediated transformation system. Biochim Biophys Acta 1722:189-199

Sitkiewicz I (2018) How to become a killer, or is it all accidental? Virulence strategies in oral streptococci. Mol Oral Microbiol 33:1-12

Sitkiewicz I, Musser JM (2006) Expression microarray and mouse virulence analysis of four conserved two-component gene regulatory systems in group a streptococcus. Infect Immun 74:1339-1351

Slager J, Kjos M, Attaiech L, Veening J-W (2014) Antibiotic-induced replication stress triggers bacterial competence by increasing gene dosage near the origin. Cell 157:395-406

Smith HE, Wisselink HJ, Vecht U, Gielkens AL, Smits MA (1995) Highefficiency transformation and gene inactivation in Streptococcus suis type 2. Microbiology 141(Pt 1):181-188

Son M, Ghoreishi D, Ahn S-J, Burne RA, Hagen SJ (2015) Sharply tuned $\mathrm{pH}$ response of genetic competence regulation in Streptococcus mutans: a microfluidic study of the environmental sensitivity of comX. Appl Environ Microbiol 81:5622-5631

Spizizen J (1958) Transformation of biochemically deficient strains of Bacillus subtilis by deoxyribonucleate. Proc Natl Acad Sci U S A 44:1072-1078

Tovpeko Y, Morrison DA (2014) Competence for genetic transformation in Streptococcus pneumoniae: mutations in $\sigma \mathrm{A}$ bypass the comW requirement. J Bacteriol 196:3724-3734

Vossen JM, van der Kok J, Venema G (1985) Construction of cloning, promoter-screening, and terminator-screening shuttle vectors for Bacillus subtilis and Streptococcus lactis. Appl Environ Microbiol 50:540-542

Woskow SA, Kondo JK (1987) Effect of proteolytic enzymes on transfection and transformation of Streptococcus lactis protoplasts. Appl Environ Microbiol 53:2583-2587 